\title{
Four beliefs that may impede progress in the treatment of smoking
}

\author{
John R Hughes
}

\begin{abstract}
The validity of four often-cited statements about smoking cessation is reviewed and their misinterpretation is discussed. "Most smokers are interested in quitting" is true; however, more important is the fact that smokers try to quit only once every 3.5 years. Thus motivating attempts to quit and removing barriers to treatment are important. "Most smokers quit on their own" is often interpreted to mean that smokers are not nicotine dependent; however, most dependent alcoholics and drug abusers who quit, do so on their own. This statement is also often interpreted to mean that most smokers do not need therapy, but the same was said about clinical depression in the early 1900s. "Quit rates with treatment are low"; however, most successful interventions for chronic disorders are the result of a series of treatments, not just one treatment. "Medication is effective only when accompanied by psychosocial therapy" is a tenet of treatment for traditional drug abuse; however, medications such as over-the-counter nicotine replacement therapies double quit rates even in the absence of psychosocial therapy.

(Tobacco Control 1999;8:323-326)
\end{abstract}

Keywords: smoking cessation, tobacco use; treatment

\section{Introduction}

Public health advocates, administrators, legislators, etc, have begun to focus on cessation for smokers. This has occurred, in part, because of the realisation that there is a lag of 30 to 40 years before the benefits of prevention are realised, whereas the benefits of cessation occur within as little as one year. ${ }^{1}$ This article discusses four commonly heard statements about smoking cessation and argues that these statements are either invalid or are often misinterpreted and thus may impede progress in the treatment of smoking.

University of Vermont, Department of Psychiatry, 38 Fletcher Place, Burlington, Vermont 05401-1419, USA;

john.hughes@uvm.edu J R Hughes

"Most smokers are interested in quitting" Several government publications and scientific articles have asserted this fact, for example, refs $^{12}$ In the most recent United States survey, $68 \%$ of smokers stated that they were "interested" in quitting. ${ }^{3}$ This result is encouraging in that it indicates that many smokers should be willing to discuss smoking cessation with clinicians and might be susceptible to our treatments. However, a common misinterpretation of this result is that smokers are already motivated to quit and we just need to avail them of treatments. However, if the question is asked in a more concrete way: "Are you planning on quitting in the next month?", less than $20 \%$ agree. ${ }^{4}$ If we go by what smokers do, rather than what they say, we obtain a similar picture. The average smoker in the United States has smoked for 19 years and made 5.3 quit attempts ${ }^{5}$; thus on average a smoker tries to stop once every 3.5 years. In a given year, most smokers (two-thirds) do nothing at all about their smoking.

In reality we need to focus as much effort on interventions to prompt cessation attempts as on devising new treatments. The traditional methods to prompt cessation have focused on physician or clinician advice ${ }^{23}$ and on increasing motivation via the media. ${ }^{6}$ Novel interventions such as those based on stages of change, ${ }^{7}$ motivational interviewing, ${ }^{8}$ and reducing smoking ${ }^{9}$ are currently being evaluated as methods to prompt quit attempts.

The complementary action to increase motivation should be the removal of barriers to quitting, especially barriers to receiving treatment. The best example of this has been the switch of nicotine gum and patches to over-the-counter (OTC) status in the United States. This single event produced an extra 3.8 million quit attempts and an estimated extra 630000 successful quitters in the United States in one year. ${ }^{10}$ It is particularly important for public health and tobacco control advocates to take note of this finding because it negates the common view that pharmacotherapy can never be a cost-effective use of tobacco control monies. This view is based on the notion that all pharmacotherapy requires substantial amounts of physician time which is expensive. However, the cost per quitter with OTC nicotine replacement therapy (NRT) is quite small. ${ }^{11}$

Another example of a way to increase motivation is reducing the cost of treatment. In several studies, providing free nicotine gum increased quit rates by $2.0-2.4$-fold and this cost appeared to be recovered in reduced healthcare expenditures. ${ }^{12-15}$

A third example is to make telephone counselling available. Several studies, ${ }^{16}$ including 
some of supplemental therapies to NRT, ${ }^{17}$ have found helplines to be effective.

\section{"Most smokers who quit, quit on their own without treatment"}

In past surveys, $90-95 \%$ of American former smokers stated that they quit on their own. ${ }^{18}$ Although the $90-95 \%$ figure was true once, ${ }^{18}$ it is no longer correct. ${ }^{19} \mathrm{~A}$ recent analyses examined American pharmaceutical company sales of NRT and bupropion for the last two quarters of 1998 . If one assumes $95 \%$ of use of medications is for smoking cessation ${ }^{20}$ and that the quit rate with medications is $10 \%,{ }^{21}$ then with the entry of OTC NRT and bupropion, $37 \%$ of all quits in 1998 in the United States were associated with medication use. ${ }^{19}$

The statement is also often misinterpreted to indicate that most smokers are not nicotine dependent; that those with real dependencies can only quit with treatment. In fact, although many people believe that most alcoholics who recover do so via Alcoholics Anonymous, over $75 \%$ of successful recoveries from alcoholism are achieved without treatment. ${ }^{22}$ Self-recovery is also more common than treatment-induced recovery among those who are dependent on heroin and cocaine. ${ }^{23}$

The $90-95 \%$ statistic is also often interpreted as indicating that most smokers do not need therapy. The fallacy of this logic can be illustrated with a historical analogy. In the early 1900 s, among those who recovered from a true depression, over $90 \%$ who did so, did it on their own. Few clinicians or administrators thought of depression as a disorder at that time. Most believed it could be cured by simple motivation and, thus, few treatment resources were made available. Nowadays almost all clinicians and administrators agree that clinical depression needs treatment, that there are effective treatments, that making such treatment readily available improves public health, and that treatment is worthy of reimbursement. Perhaps administrators', clinicians', and the public's understanding of nicotine in the 1990s is where the understanding of depression was in the early 1900s.

Many administrators and clinicians are unaware of the huge, well accepted dataset that smokers benefit from treatment. ${ }^{21}$ Others choose to ignore this dataset, often because they or someone they know quit on their own. This is especially tragic given that we currently have six, well proven, very efficacious therapies $^{21}$ (behaviour therapy, nicotine gum, patches, nasal spray, and inhaler, and bupropion). In addition, there is some evidence that with ongoing social pressure, future smokers will be those with higher levels of nicotine dependence ${ }^{24}$ or comorbid psychosocial problems. ${ }^{25}$ Clinicians believe that many, if not most, of these smokers will not quit with simple motivation, no matter how effective the media campaigns. These smokers need treatment to have a decent chance of quitting. Thus, for example, cessation monies from American tobacco settlements should go not only into advertising to motivate cessation, but also into treatment infrastructure or into the provision of treatment itself. ${ }^{26}$

"Quit rates with most therapies are low" Several articles opined this view. ${ }^{12}$ In most meta-analyses, long-term quit rates from treatment are $20-25 \% .{ }^{27}$ The implicit connotation is that we should expect higher quit rates. The problem is twofold.

First, nicotine dependence, like all drug dependencies, is a chronic, relapsing disorder. In other chronic disorders such as diabetes, any given intervention - changing the dose of insulin, for example - has a small effect on overall outcome; however, the cumulative effect of interventions, such as 20 years of care by a specialist, can have a large impact. Thus, these administrators, public health advocates, and treating clinicians need to accept the notion that the goal, when treating smoking, is not so much success on any one given attempt, but is rather the achievement of eventual success in a given individual in as short a time as possible. For some this will occur with the first attempt, for others it will not be until the fourth attempt.

With other chronic relapsing disorders such as arthritis, a major focus has been on having a single clinician providing care with multiple regular follow-ups and seeing the patient through exacerbations and remissions. Current usual care for smoking is just the opposite. Even in the United States, many health maintenance organisations provide smoking cessation therapy as a once-in-a-lifetime option. Systems in which providers or the media repeatedly prompt quit attempts and provide therapy probably have the best chance of inducing long-term cessation.

The second problem is that a much more stringent definition of success is used-for example, no smoking at all, not even a puff, at weeks $1,2,3,4,12,26$, and 52 of follow-up among all those who enter treatment-than most fields in psychology or medicine. (For drug dependencies, for example, the criterion is usually reduced drug use at early follow-up among those who completed treatment.) In fact, if similar stringent criteria are used, longterm abstinence rates for alcohol dependence are similar to that for smoking- $25 \%$ or less. ${ }^{28-30}$

The "low" rates for smoking cessation are also often compared with "remission rates" of $70 \%$ for the treatment of other behavioural disorders such as depression. The problem again is one of comparing apples and oranges. The criterion for remission in depression is relief of acute symptomatology. If a similar criterion is used for nicotine - relief of withdrawal - then medications could also claim a $70 \%$ success rate ${ }^{27}$ On the other hand, if the criterion for successful treatment of depression, among all who were offered medication, was a normal score on the Beck Depression Inventory for weeks 1-4, 12, 26 , and 52 of follow-up, the rate of success for antidepressants would probably be $25 \%$ or less. 
"Medication is effective only when accompanied by a psychosocial therapy"

The Food and Drug Administration label on all smoking cessation products states they are "recommended for use as part of a comprehensive behavioral smoking cessation program". The statement is based on the clinical belief that, for "traditional" drug dependencies such as alcohol, opioids, and cocaine, medications alone cannot induce a success. Interestingly, whether this statement is actually true for alcohol and other dependencies has been empirically tested in only a handful of experiments with mixed results. ${ }^{31}$

In terms of nicotine dependence, several true experiments and several meta-analytical reviews have clearly shown that medications double quit rates, independent of adjunctive psychosocial therapy, and these medications can work even in the absence of such therapy. $^{32} 33$ The repeated success of OTC NRT in controlled trials is further evidence that medications can work without "talking" therapies. ${ }^{21}$ Seven studies of OTC patches and gum have tested NRT without any clinician-patient interaction. All found that OTC NRT either increased quit rates over placebo or produced quit rates similar to that found with "real world" physician-patient interactions. ${ }^{21}$

This is not to say that behavioural and other adjunctive therapies are not effective-they do boost quit rates when given alone and when added to medication. ${ }^{32} 33$ Although use of such therapies is desirable, however, they are not essential to the success of medication.

Recognising the efficacy of medications alone is very important as most smokers do not attend talking therapies ${ }^{34}$ for the following reasons. ${ }^{35}$ Unlike alcoholism, the notion that, for some, stopping smoking requires new learning or insight has not been well accepted by the public.

Problems exist, not with smokers, but with the healthcare system, for example: unlike alcohol and drug dependencies, most healthcare workers do not know where to refer smokers; the number of chemical dependency counsellors, physicians, psychologists, social workers, etc in the United States who are competent to treat nicotine dependence is ridiculously small compared with the scale of the problem; in most locales, talking therapy for smoking cessation is available only two or three times per year. (Consider if this were the case for alcoholism or cocaine addiction!) Unlike therapy for depression, for most smokers there is no reimbursement for talking therapies for smoking. ${ }^{36}$ Despite this, many healthcare plans insist on attendance at behaviour therapy sessions.

There are two major implications here. First, requiring attendance at talking therapy sessions to obtain medication for smoking is without scientific basis and should be seen as a way to inhibit costs, not to promote health. Second, recognising that behaviour therapy clearly boosts quit rates, federal programmes, and health maintenance organisations should make behaviour therapy as accessible to smokers as therapy for other scientifically based treatments.

\section{Conclusions}

The area of tobacco control is probably one of the best examples of science helping out policy. To continue to move forward, we must examine our beliefs about smoking cessation and treatment of smoking and change them when the science contradicts them.

The writing of this article was funded by Research Scientist Award DA-00109 from the National Institute on Drug Abuse, Rockville, Maryland, USA.

1 US Department of Health and Human Services. The health benefits of smoking cessation. A report of the Surgeon General, 1990. Rockville, Maryland: Public Health Service, Centers for Disease Control, Office on Smoking and Health, 1990. (DHHS Publication No (CDC) 90-8416.)

2 Fiore MC, Bailey WC, Cohen SJ, et al. Smoking cessation. Clinical Practice Guideline No 18. Rockville, Maryland: US Department of Health and Human Services, Public Health Service, Agency for Health Care Policy and Research, April 1996. (AHCPR Publication No 960692.)

3 US Centers for Disease Control and Prevention. Cigarette smoking among adults-United States, 1995. MMWR 1997;46:1217-20.

4 Etter JF, Perneger TV, Ronchi A. Distributions of smokers by stage: international comparison and association with by stage: international comparison and associt
smoking prevalence. Prev Med 1997;26:580-5.

5 Yankelovich Partners. Smoking cessation study. New York: American Lung Association, 1998.

6 Flay BR. Selling the smokeless society: 56 evaluated mass media programs and campaigns worldwide. Washington, DC: American Public Health Association, 1987.

7 Prochaska JO, DiClemente CC, Velicer WF, et al. Standardized, individualized, interactive and personalized self-help programs for smoking cessation. Health Psychol 1993; 12:399-405.

8 Miller WR, Rolnick S. Motivational interviewing: preparing people to change addictive behavior. New York: Guilford Press, 1991 .

9 Hughes JR. Reducing smoking: an introduction and review of the evidence. Addiction 1999. (In press.)

10 Shiffman S, Pinney JM, Gitchell J, et al. Public health benefit of over-the-counter nicotine medications. Tobacco Conefit of over-the-counter
trol $1997 ; 6: 306-10$.

11 Cromwell J, Bartosch WJ, Fiore MC, et al. Costeffectiveness of the clinical practice recommendations in the AHCPR Guideline for Smoking Cessation. FAMA 1997;278:1759-66.

12 Hughes JR, Wadland WC, Fenwick JW, et al. Effect of cost on the self-administration and efficacy of nicotine gum: a preliminary study. Prev Med 1991;20:486-96.

13 Cox JL, McKenna JP. Nicotine gum: does providing it free in a smoking cessation program alter success rates? $\mathrm{f}$ Fam Pract 1990;31:278-80.

14 Johnson RE, Stevens VJ, Hollis JF, et al. Nicotine chewing gum use in the outpatient care setting. F Fam Pract 1992; gum use

15 Curry SJ, Grothaus LC, McAfee T, et al. Use and cost effectiveness of smoking-cessation services under four insurance plans in a health maintenance organization. $N$ Engl f Med 1998;339:673-9.

16 Lichtenstein E, Glasgow RE, Lando HA, et al. Telephone counseling for smoking cessation: rationales and metaanalytic review of evidence. Health Educ Res 1996;11:24357.

17 Shiffman S, Paty JA, Rohay J, et al. The efficacy of computer-tailored smoking cessation material as a supplement to nicotine patch therapy. Nicotine Tobacco Res 1999. (In press.)

18 Fiore MC, Novotny TE, Pierce JP, et al. Methods used to quit smoking in the United States. $\mathscr{f} A M A$ 1990;263:2760-5.

19 Hughes JR. Impact of medications on smoking cessation. In: Burns D, ed. Population impact of smoking cessation. In: Burns D, ed. Population impact of smoking cessation interventions. Bethesda, Maryland. Nates of Health, National Cancer Institute, 1999. (NCI Smoking and Tobacco Control Monograph, in press.)

20 Pillitteri JL, Hughes JR, Callas PA. Use of nicotine gum for smoking reduction versus smoking cessation, Nicotine Tobacco Res 1999. (In press.)

21 Hughes JR, Goldstein MG, Hurt RD, et al. Recent advances in pharmacotherapy of smoking. FAMA1999;281:72-6.

22 Sobell LC, Cunningham JA, Sobell MB. Recovery from alcohol problems with and without treatment: prevalence in two population surveys. Am f Public Health 1996; 86:966-72.

23 Gerstein DR, Harwood HJ. Treating drug problems: a study of the evolution, effectiveness, and financing of public and private drug treatment systems. Washington, DC: National Academy Press, 1990. 
24 Fagerström K-O, Kunze M, Schoberberger JC, et al. Nicotine dependence versus smoking prevalence: comparisons Control 1996;5:52-6.

25 Hughes JR. Comorbidity and smoking. Nicotine Tobacco Res 1999. (In press.)

26 Pinney JM, Glynn T, Gruman J, et al. Treating tobacco dependence in the US: ad hoc group findings and recommendations. Washington, DC: Center for the Advancement of Health, 1998.

27 Hughes JR. Pharmacotherapy of nicotine dependence. In: Schuster CR, Kuhar MJ, eds. Pharmacological aspects of drug dependence: toward an integrative neurobehavioral approach. Handbook of Experimental Pharmacology Series. New York: Springer-Verlag, 1996:599-626.

28 Agosti V. The efficacy of controlled trials of alcohol misuse treatments in maintaining abstinence: a meta-analysis. Int f Addict 1994;29:759-69.

29 Chick J, Ritson B, Connaughton J, et al. Advice versus extended treatment for alcoholism: a controlled study. $\mathrm{Br} \mathcal{F}$ Addict 1988;83:159-70.

30 Wilde MJ, Wagstaff A. Acamprosate: a review of its pharmacology and chemical potential in the management of alcohol dependence after detoxification. Drugs 1997;53:103853.
31 Onken LS, Blaine JD, Boren JJ, eds. Integrating behavioral therapies with medications in the treatment of drug dependence. Rockville, Maryland: National Institute on Drug Abuse, 1995. National Institute on Drug Abuse Research Monograph 150

32 Hughes JR. Combining behavioral therapy and pharmacotherapy for smoking cessation: an update. In: Onken LS, Blaine JD, Boren JJ, eds. Integrating behavior therapies with medication in the treatment of drug dependence. Rockville, Maryland: National Institute on Drug Abuse, 1995.92109. National Institute on Drug Abuse Research Monograph 150 .

33 Hughes JR. Combined psychological and nicotine gum treatment for smoking: a critical review. $\mathcal{F}$ Substance Abuse 1991;3:337-50.

34 Lichtenstein E, Hollis JF. Patient referral to a smoking cessation program: who follows through? f Fam Pract 1992;34:739-44.

35 Hughes JR. Pharmacotherapy for smoking cessation: unvalidated assumptions, anomalies and suggestions for further research. F Consult Clin Psychol 1993;61:751-60.

36 Schauffler HH, Parkinson MD. Health insurance coverage for smoking cessation services. Health Educ $Q 1993$ 20:185-206.

\section{Tobacco Control at tobaccocontrol.com}

Visitors to the world wide web can access Tobacco Control through the BMJ Publishing Group's home page http://www.bmj.com or directly using its individual URL

http://www.tobaccocontrol.com. There they will find the following.

- Full text of all issues from Summer 1999 onward (open access to all until February 2000, and thereafter only to subscribers via password)

- Facility to send a rapid response to any article in the journal

- Contents lists of previous issues

- Members of the editorial board

- Subscribers' information

- Instructions for authors

- Details of reprint services.

A hotlink gives access to:

- BMJ Publishing Group home page

- British Medical Association web site

- Online books catalogue

- BMJ Publishing Group books

Suggestions from visitors about features they would like to see are welcomed. They can be sent to the editor at the email address on the inside front cover of this issue, or left via the opening page of the BMJ Publishing Group site or, alternatively, via the journal page, through "About this site". 